\title{
Sense of coherence, mental well-being and perceived preoperative hospital and surgery related stress in surgical patients with malignant, benign, and no neoplasms
}

Henning Krampe ${ }^{1 *}$ (D), Ute Goerling ${ }^{2}$, Claudia D. Spies ${ }^{1}$, Sina K. Gerhards' ${ }^{1}$, Sören Enge ${ }^{3}$, Anna-Lena Salz' Léonie F. Kerper ${ }^{1,4}$ and Tatjana Schnell ${ }^{5,6}$

\begin{abstract}
Background: This prospective, cross-sectional, observational study examined associations between sense of coherence (SOC), mental well-being, and perceived preoperative hospital and surgery related stress of surgical patients with malignant, benign, and no neoplasms. The objective was to assess a putative association between SOC and preoperative stress, and to test for a statistical mediation by mental well-being.

Method: The sample consisted of 4918 patients from diverse surgical fields, of which 945 had malignant neoplasms, 333 benign neoplasms, and 3640 no neoplasms. For each subsample, we conducted simple mediation analyses to test an indirect effect of SOC on preoperative stress mediated by mental well-being. The models were adjusted for age, gender, and essential medical factors.

Results: Patient groups did not differ significantly regarding degrees of SOC and mental well-being (SOC, M [SD]: 12.31 [2.59], 12.02 [2.62], 12.18 [2.57]; mental well-being M [SD]: 59.26 [24.05], 56.89 [22.67], 57.31 [22.87], in patients with malignant, benign, and without neoplasms, respectively). Patients without neoplasms reported significantly lower stress (4.19 [2.86], M [SD]) than those with benign (5.02 [3.03], M [SD]) and malignant neoplasms (4.99 [2.93], $\mathrm{M}[\mathrm{SD}]$ ). In all three mediation models, SOC had significant direct effects on stress, with higher SOC being associated with lower stress $\left(-0.3170\right.$ [0.0407], -0.3484 [0.0752], -0.2919 [0.0206]; $c^{\prime}$ [SE], $p<0.001$ in patients with malignant, benign, and without neoplasms, respectively). In patients with malignant neoplasms and without neoplasms, SOC showed small indirect effects on stress that were statistically mediated by well-being. Higher SOC was related to higher well-being, which in turn was related to lower stress. In patients with benign neoplasms, however, no significant indirect effects of SOC were found.

\footnotetext{
* Correspondence: henning.krampe@charite.de

'Department of Anesthesiology and Operative Intensive Care Medicine (CCM, CVK), Charité - Universitätsmedizin, corporate member of Freie Universität Berlin, Humboldt-Universität zu Berlin, and Berlin Institute of Health, Charitéplatz 1, 10117 Berlin, Germany

Full list of author information is available at the end of the article
}

(c) The Author(s). 2020 Open Access This article is licensed under a Creative Commons Attribution 4.0 International License, which permits use, sharing, adaptation, distribution and reproduction in any medium or format, as long as you give appropriate credit to the original author(s) and the source, provide a link to the Creative Commons licence, and indicate if changes were made. The images or other third party material in this article are included in the article's Creative Commons licence, unless indicated otherwise in a credit line to the material. If material is not included in the article's Creative Commons licence and your intended use is not permitted by statutory regulation or exceeds the permitted use, you will need to obtain permission directly from the copyright holder. To view a copy of this licence, visit http://creativecommons.org/licenses/by/4.0/ The Creative Commons Public Domain Dedication waiver (http://creativecommons.org/publicdomain/zero/1.0/) applies to the data made available in this article, unless otherwise stated in a credit line to the data. 
(Continued from previous page)

Conclusions: SOC was directly associated with lower perceived hospital and surgery related stress, over and above the direct and mediation effects of mental well-being. Because the data are cross-sectional, conclusions implying causality cannot be drawn. Nevertheless, they indicate important relationships that can inform treatment approaches to reduce elevated preoperative stress by specifically addressing low SOC.

Trial registration: clinicaltrials.gov Identifier: NCT01357694. Registered 18 May 2011

Keywords: Cancer, Depression, Mediation analysis, Mental well-being, Neoplasm, Preoperative, Sense of coherence, Stress

\section{Background}

Perceived preoperative stress is common among surgical patients, and it has mainly been investigated in the form of acute preoperative anxiety [1-6]. In contrast to general emotional distress, the experience of acute preoperative stress is particularly related to unpleasant feelings concerning the impending surgery and hospital treatment [2, 4, 7-9]. Preoperative stress can by itself be regarded as a negative patient reported outcome $[2,4]$. Moreover, it is associated with peri- and postoperative complications and worse surgical outcomes [2, 7, 9-16]. So far, oncological studies have rarely investigated preoperative stress as primary outcome. Instead, numerous studies have focused on general emotional distress unrelated to surgery, which has been a major target of both clinical practice and psycho-oncological research for a long time [17-21]. Little is known about the relative degree of distress experienced by cancer patients before surgery compared to non-cancer patients. Three studies found higher state anxiety in cancer patients [22$24]$, while another study did not find any significant differences [25].

Previous studies demonstrated that several patient characteristics and clinical factors were associated with preoperative stress, such as gender [22, 25, 26], mental health [22], preoperative physical health [22], surgical field [1] and extent of surgical procedure [5, 27]. Further knowledge on related factors may contribute to both our understanding of preoperative stress and the improvement of treatment approaches. Individual resources like sense of coherence (SOC) that may help patients to cope with stress are of particular interest. SOC is defined as a person's view of the world in terms of a basic confidence that one's own life is comprehensible, manageable, and meaningful [28, 29]. Positive associations of SOC with health and quality of life have frequently been shown [3032]. According to the salutogenetic model by Antonovsky, people with a high SOC are more successful in coping with stressful life events and problems, which results in less perceived distress and better health. SOC has shown robust associations with aspects of mental health like quality of life, mental well-being, and clinical symptoms of anxiety and depression [29-31, 33]. A recent meta-analysis found that in cancer patients, there is a substantial negative association of SOC and general emotional distress, which is independent of age, gender, disease stage, and days since diagnosis [33]. To our knowledge, there are no studies on the relationship of SOC and acute perceived preoperative stress in surgical patients with cancer, but it seems likely that SOC and preoperative stress are also negatively related.

Concerning the role of mental well-being, it might be hypothesized that SOC results in higher mental well-being and this in turn reduces distress like, e.g., acute preoperative stress. In this case, mental wellbeing would serve as a mediator between SOC and low acute preoperative stress. Because the present investigation is based on cross-sectional data, causal relationships cannot be established [34, 35]. Two lines of reasoning would support the mentioned direction, however. One is the empirically validated assumption that SOC and meaning in life, which Antonovsky claimed to be the most important element in SOC [28], actually affect subjective well-being and stress perception [36-39], as well as functional health outcomes [40-42]. Additionally, one might bring forward the argument that the most stable factor would best represent the independent variable. Both SOC and meaningfulness are psychological dispositions that have a tendency to increase over the lifespan, but they are known to be relatively stable over several years [39, 43-46]. The extent of mental well-being is, similar to symptoms of anxiety and depression, less stable and changes over medium-term periods of time [47-49], while acute preoperative stress is a state variable that changes within shortterm intervals $[9,50]$. It is therefore plausible to conceive of SOC as the independent factor, acute perceived preoperative stress as the dependent variable, and mental well-being as a potential mediating factor.

This study examined associations between SOC, mental well-being, and perceived preoperative hospital and surgery related stress of surgical patients with malignant, benign, and no neoplasms. The objective was to assess a putative association between SOC and preoperative stress, and to test for a statistical mediation by mental well-being. 


\section{Methods}

\section{Setting, study design, ethics approval and consent to participate}

This cross-sectional, prospective, observational study conducted secondary mediator analyses on data from the research project Bridging Intervention in Anesthesiology (BRIA).

We investigated three groups of surgical patients, those with malignant, benign, and no neoplasms. For each patient group, we conducted a simple mediation model that tested the indirect effect of SOC on perceived hospital and surgery related stress mediated through mental well-being. The models were adjusted for demographic and clinical factors that are potentially related to perceived preoperative stress. These covariates included age, gender, preoperative physical health, surgical field, severity of medical comorbidity, as well as extent of surgical procedure. In the samples of patients with neoplasms, additional analyses were conducted including tumor site as covariate. In order not to confuse preoperative stress with preoperative symptoms of clinical anxiety, we explicitly assessed perceived stress with items relating to the impending surgery and treatment in hospital.

The BRIA project was approved by the Institutional Review Board of Charité - Universitäts medizin Berlin [EA1/014/11], registered with ClinicalTrials.gov [Identifier: NCT01357694], and conducted in compliance with the Helsinki Declaration. All participants provided written informed consent for all procedures. The full details of the setting, patient recruitment and assessment instruments are available in our previous publications $[51,52]$.

\section{Data collection and eligibility criteria}

By means of a computer-assisted psychosocial selfassessment, we collected patient-reported data in the preoperative assessment clinics of the Charité - Universitätsmedizin Berlin, Campus Charité Mitte and Campus Virchow Klinikum, Berlin, Germany, from May 2011 to August 2012.

Six months after preoperative assessment, we obtained medical data from the electronic patient data management system of the hospital, and determined six measures to assess essential medical parameters. All categories of these medical measures are shown in Table 1; more details are available in our previous publications $[53,54]$. The six parameters included:

1. Overall indicator of physical health status: Evaluation of patients' perioperative risk according to the ASA (American Society of Anesthesiologists) physical status classification system $[55,56]$.

2. Surgical field: Neuro-, head, and neck surgery; abdomino-thoracic surgery; peripheral surgery [53, 57].
3. Severity of medical comorbidity: Charlson Comorbidity Index (CCI) [58].

4. Extent of surgical procedures: Item 'operative severity' of the POSSUM scoring system (Physiological and Operative Severity Score for the enUmeration of Mortality and Morbidity) [59, 60].

5. Site of tumor: Based on ICD-10 codes of patients' primary diagnoses, 14 sites of tumor were determined for both malignant and benign tumors.

6. Status of tumor: Malignant, benign, and suspect neoplasms.

Inclusion criteria were written informed consent to participate after having been properly instructed; patient of the preoperative anesthesiological assessment clinic, and age above 17 years. Exclusion criteria were surgery with an emergency or urgent indication; inability to attend the preoperative assessment clinic; insufficient knowledge of German language; being a member of the hospital staff; admitted in police custody; accommodation in an institution by official or court order; being under guardianship, and psychiatric, neurological or other conditions associated with limited legal capability or limited capability of being properly instructed or giving informed consent. Figure 1 shows the flowchart of the inclusion process. Of the 5102 patients enrolled in the preoperative computer-assisted self assessment, data of 184 patients were not applicable for data analyses, either because planned surgeries were cancelled, or because of surgeries due to suspect neoplasms. In total, data of 4918 patients were included in the statistical analyses.

\section{Patient-reported outcome measures}

Outcomes included measures of SOC, mental wellbeing, and perceived hospital and surgery related stress.

\section{Sense of coherence}

We assessed SOC with the Brief Assessment of Sense of Coherence (BASOC) [61], a 3-item short version of the Sense of Coherence Scale 29 (SOC-29 [29]. The items are rated on a 5 -point scale from 1 to 5 , with sum scores ranging from 3 to 15 , and higher scores indicating higher SOC. The BASOC has proven superior to the commonly used 3-item measure SOC-3 concerning reliability and validity [61]. With a Cronbach's alpha of .71, the BASOC showed a comparatively good reliability for a short 3-item questionnaire measure; indicators of construct validity were also adequate in terms of a correlation of $r=0.77$ between BASOC and SOC-29, excluding the three BASOC items, and correlations with different mental-health-related parameters between $r=$ .45 to $r=.63$ [61]. In the present study, the internal consistency of the BASOC was even better than in the 


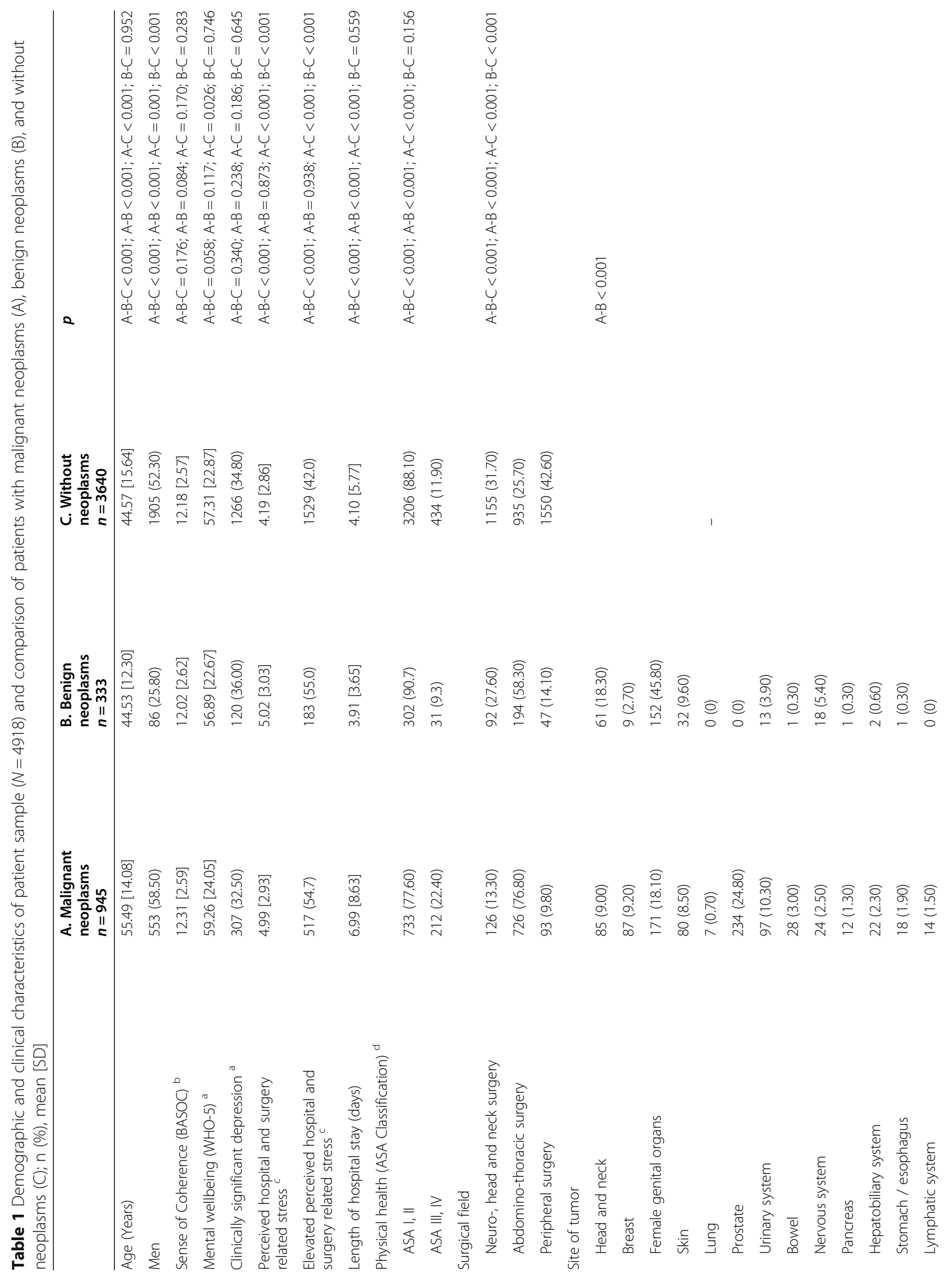




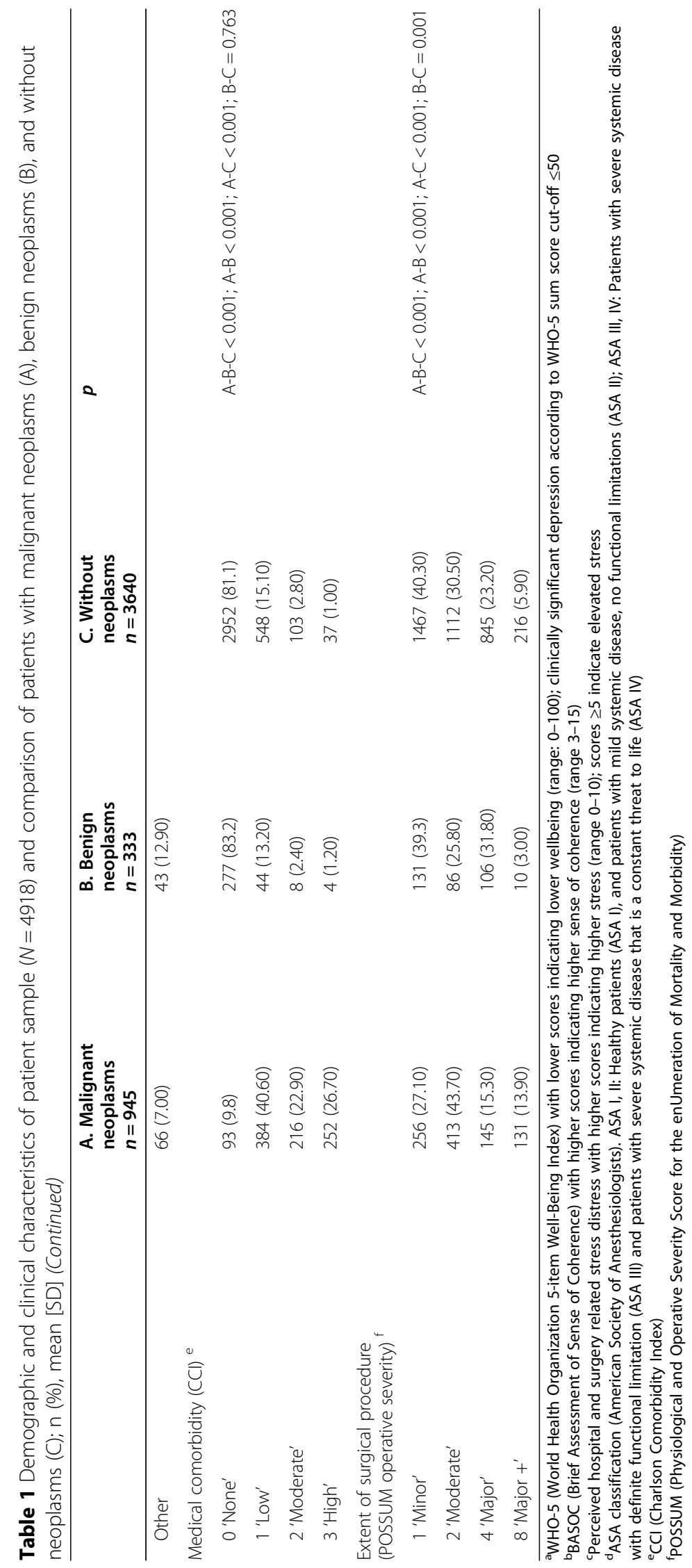




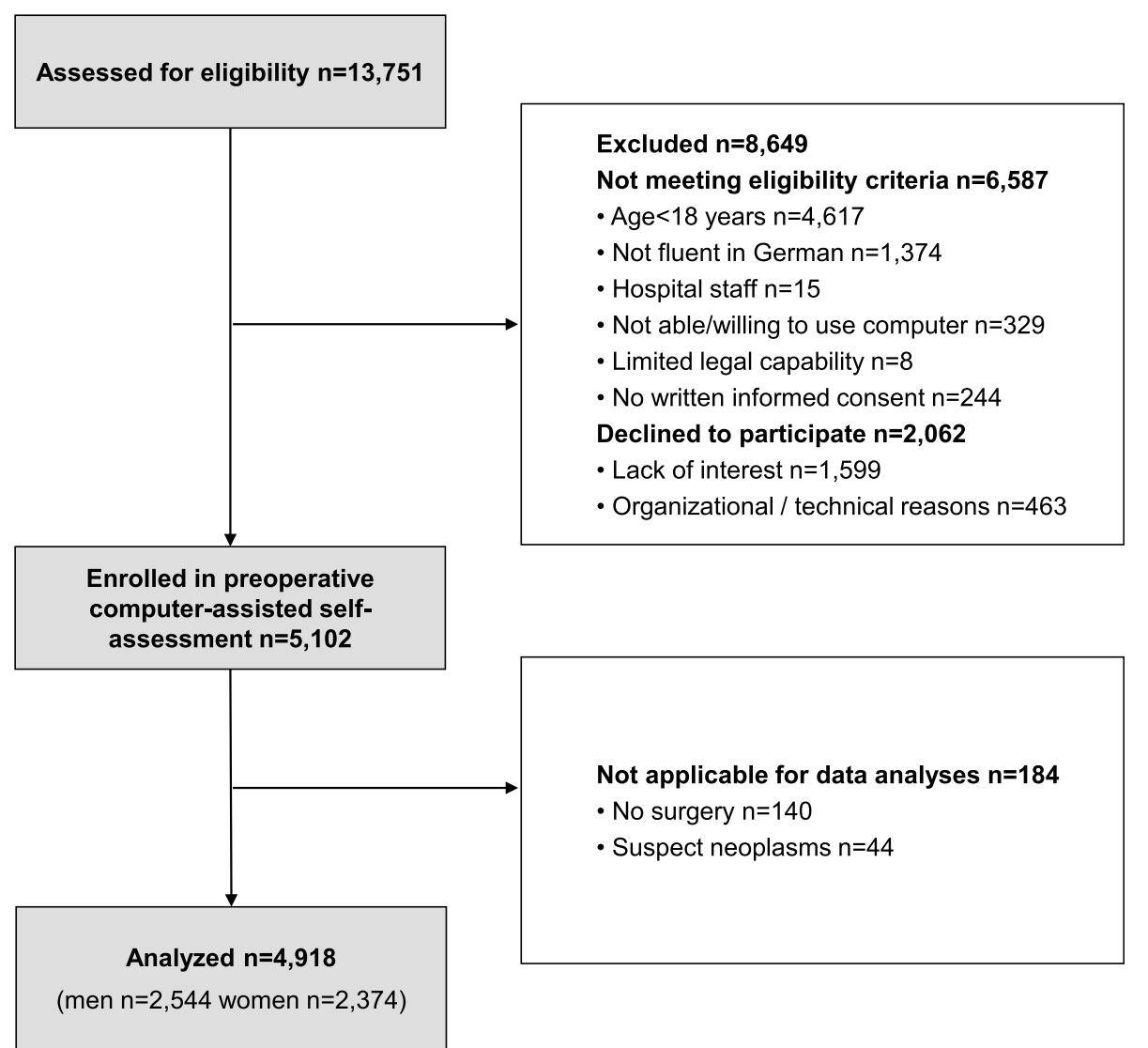

Fig. 1 Flow diagram of study participants

validation study by Schumann et al. (2003), with a Cronbach's alpha of 0.74 .

\section{Mental well-being}

The short self-report questionnaire World Health Organization Well-Being Index (WHO-5) assesses subjective mental well-being over the past 2 weeks $[47,49,62]$. It consists of five items covering sensations of cheerfulness, calm, activity, freshness, and interest. Respondents rate how often they have experienced the described sensations on a 6-point scale from 0 (at no time) to 5 (all of the time), resulting in a raw sum score from 0 to 25 , with higher scores indicating better well-being. The sum score is multiplied by 4 in order to yield a transformed scale score ranging from 0 to 100 . The WHO-5 is also applied as a screening tool to identify depression by measuring decreased well-being. A sum score of 50 or less indicates clinically relevant depression $[47,49]$. The WHO-5 has shown good internal consistency with Cronbach's alphas between .84 and $.95[47,63]$ and good retest reliability, as indicated by an intraclass correlation coefficient of .81 [48]. A recent systematic literature review found numerous articles demonstrating that the WHO-5 has high validity as both a measure of mental well-being as well as a screening tool for clinically significant depression [49]. In the present study, the internal consistency of the WHO-5 is high, with a Cronbach's alpha of .87 .

Perceived preoperative hospital and surgery related stress The perceived preoperative hospital and surgery related stress was measured with an adapted version of the Distress Thermometer [64], using two vertical numerical rating scales from 0 (no stress at all) to 10 (extreme stress) illustrated as a thermometer. The first item had the instruction "Please choose the number ( 0 to 10$)$ that best represents the stress you are experiencing because of the upcoming hospital stay", and the second item had the instruction "Please choose the number ( 0 to 10 ) that best represents the stress you are experiencing because of the upcoming surgery". The two items correlated highly with each other with a Pearson correlation coefficient of $r=0.87$. Thus, they were added up and their mean sore was used in the analysis. Exploratory analyses in a subset of the sample $(n=2320)$ showed high correlations of state anxiety, measured by the state scale of the State Trait Anxiety Inventory (STAI) [65], with the hospital related distress item $(r=0.59)$, the surgery related distress item $(r=0.62)$, and the mean score of the two items $(r=0.63)$. For an 

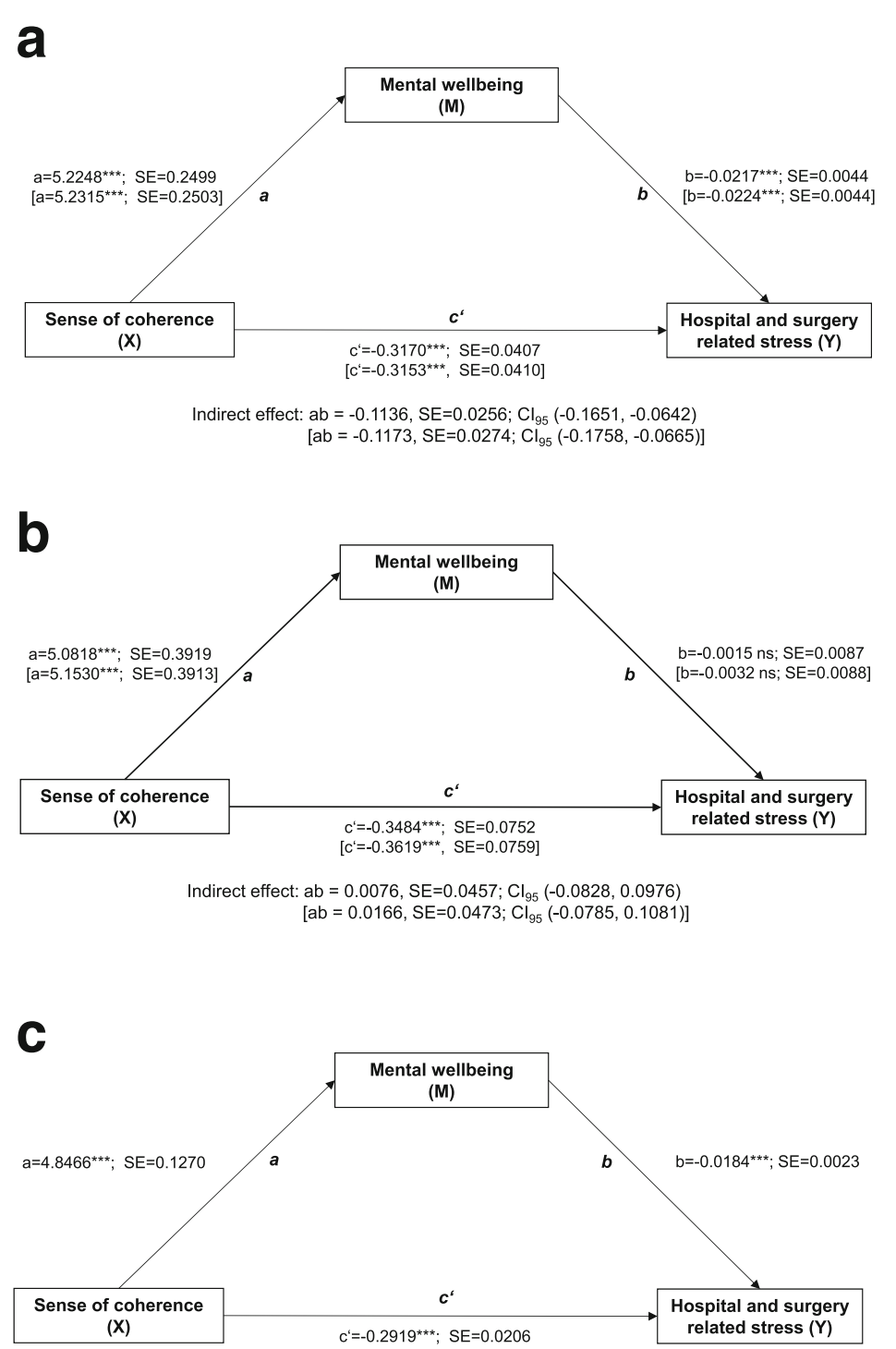

Indirect effect: $\mathrm{ab}=-0.0892, \mathrm{SE}=0.0116 ; \mathrm{Cl}_{95}(-0.1116,-0.0668)$

Fig. 2 a, b, c. Mediation models of the effect of sense of coherence $(S O C)(X)$ on perceived hospital and surgery related stress $(Y)$ through mental well-being (M). Regression models adjusted for age, gender, physical health (ASA classification), surgical field, medical comorbidity (CCI), and extent of surgical procedure (POSSUM operative severity item). Data in brackets: Regression model additionally adjusted for site of tumor. a. Patients with malignant neoplasms $(n=945)$. b. Patients with benign neoplasms $(n=333)$. c. Patients without neoplasms $(n=3640)$

exploratory estimate of elevated perceived preoperative stress we used a cut-off point of $\geq 5$, as has been recommended for visual analogue scales of preoperative anxiety [66].

\section{Statistical analyses}

Our primary objective was to investigate to what extent the putative relation between SOC and perceived preoperative hospital and surgery related stress would be mediated by mental well-being in surgical patients with malignant neoplasms, benign neoplasms, and no neoplasms. We conducted three simple mediation analyses using the PROCESS macro, version 3.2, for SPSS [34, 35]. The analyses were based on two multiple linear regression models. Both models simultaneously included the independent factor SOC, as measured with the BASOC sum score, and the covariates age in years, gender, preoperative physical health (ASA), surgical field, severity of medical comorbidity $(\mathrm{CCI})$, as well as extent of surgical procedure (POSSUM operative severity item). In the two samples of patients with neoplasms, analyses were first conducted without adjusting for tumor site, and thereafter with tumor site as covariate. Categorical covariates with more than two categories were dummy coded before being 
entered as several dummy variables in the regression models. In order to avoid calculation errors in bootstrapping analyses, tumor site categories with fewer than 8 cases were collapsed into the category 'other'.

The first regression model predicted mental wellbeing as measured with the WHO-5 sum score. The second model included the WHO-5 sum score in the set of predictor variables and predicted perceived preoperative hospital and surgery related stress. The different relationships of the factors of the mediation analyses are shown by path diagrams illustrating the unstandardized ordinary least squares (OLS) regression coefficients of the regression models (Fig. $2 \mathrm{a}, \mathrm{b}$ and c). Paths $a$ and $c^{\prime}$ demonstrate the direct effects of the independent variable $\mathrm{X}, \mathrm{SOC}$, on the mediator, mental well-being, and on the dependent variable Y, perceived preoperative hospital and surgery related stress, respectively. Path $b$ refers to the direct effect of the mediator, mental well-being, on the dependent variable. This effect is a partial regression coefficient that is controlling for the independent variable, SOC. The indirect effect of SOC on perceived preoperative hospital and surgery related stress, mediated by mental well-being, is determined by the product of the paths $a^{*} b$. Indirect effects were tested with a percentile bootstrapping approach based on 5000 bootstrap samples [34]. An indirect effect is considered statistically significantly different from zero when the $95 \%$ bootstrap confidence intervals of the product $a * b$ do not include 0 . As effect sizes of the indirect and direct effects of SOC, we calculated the completely standardized effects $a b_{c s}$ and $c_{c s}^{\prime}$ with $95 \%$ bootstrap confidence intervals. The completely standardized effect expresses the indirect and direct effects of the independent variable $\mathrm{X}$, here $\mathrm{SOC}$, as differences in standard deviations $(\mathrm{SD})$ of the dependent variable $\mathrm{Y}$, here hospital and surgery related distress. The effect sizes are defined as $a b_{c s}=\mathrm{SD}_{\mathrm{x}}{ }^{*}\left(a b_{\mathrm{ps}}\right)$ and $\mathrm{c}_{\mathrm{cs}}^{\prime}=\mathrm{SD}_{\mathrm{x}}{ }^{*}\left(\mathrm{c}_{\mathrm{ps}}{ }^{\prime}\right)$, where $\mathrm{ab}_{\mathrm{ps}}=\mathrm{a}^{*} \mathrm{~b} / \mathrm{SD}_{\mathrm{y}}$ and $\mathrm{c}_{\mathrm{ps}}^{\prime}=\mathrm{c}^{\prime} / \mathrm{SD}_{\mathrm{y}}[34]$.
Descriptive results were expressed as relative frequencies in percent, as well as means (M) and standard deviations (SD). Bivariate correlations were tested using Pearson correlation analyses. The comparisons of patient groups with malignant neoplasms, benign neoplasms, and no neoplasms regarding demographic and clinical characteristics were conducted with Chi-square tests for categorical variables, as well as with one-way ANOVAs for all three groups, and independentsamples T-tests for pairs of groups, for metric variables. A two-tailed $p$-value $<0.05$ was considered statistically significant for all statistical tests except the bootstrapping method.

\section{Results}

Out of the 4918 study participants, 945 underwent surgery due to malignant neoplasms, 333 due to benign neoplasms, and 3640 had surgeries due to other diseases. Demographic, psychological, and clinical characteristics of the three patient groups are presented in Table 1. Patients with malignant neoplasms were older and had a higher rate of men than those with benign and no neoplasms. The groups did not differ significantly regarding either SOC or mental well-being. However, patients without neoplasms had significantly lower mean perceived hospital and surgery related stress, as well as lower rates of elevated stress than those with neoplasms. Concerning preoperative physical health, medical comorbidity, length of hospital stay, and extent of surgical procedure, the data indicated that the group with malignant neoplasms had significantly higher rates of severely impaired patients. The three groups differed significantly regarding the distribution of the surgical fields neuro-, head, and neck surgery, abdomino-thoracic surgery, as well as peripheral surgery, reflecting the diversity of included surgical patients. Finally, patients with malignant and benign neoplasms showed different distributions of sites of tumors.

Table 2 Correlations between sense of coherence, well-being, and perceived hospital and surgery related distress $(N=4918)$

\begin{tabular}{lll}
\hline & SOC & Mental well-being \\
\hline A. Patients with malignant neoplasms $(n=945)$ & $0.59^{* * *}$ & $-0.42^{* * *}$ \\
Mental well-being & \\
Perceived hospital and surgery related stress & $0.61^{* * *}$ & $-0.38^{* * *}$ \\
B. Patients with benign neoplasms $(n=333)$ & $-0.34^{* * *}$ \\
Mental well-being & $0.54^{* * *}$ \\
Perceived hospital and surgery related stress & $-0.37^{* * *}$ \\
C. Patients without neoplasms ( $n=3640)$ & $-0.23^{* * *}$ \\
Mental well-being & \\
\hline
\end{tabular}


In all three patient groups, SOC and mental well-being showed large positive bivariate correlations (.54 to .61) (Table 2). While perceived hospital and surgery related stress was moderately negatively related to SOC in all groups (-.34 to -.42$)$, its correlations with mental well-being varied between -.23 in patients with benign neoplasms and -0.38 in those with malignant neoplasms (Table 2).

\section{Simple mediation analyses}

Figure $2 \mathrm{a}, \mathrm{b}$, and $\mathrm{c}$ show the results of three simple mediation models testing indirect effects of SOC on perceived hospital and surgery related stress mediated by mental well-being. In all three models, SOC showed significant direct effects on stress, with higher SOC being associated with lower stress. The corresponding direct effect sizes $c^{\prime}{ }_{c s}$ were -0.2808 [-0.2793], -0.3014 [-0.313], and -0.2616 for the samples of patients with malignant, benign, and no neoplasms, respectively; effect sizes in brackets refer to the models additionally adjusted for sites of tumor. In patients with malignant neoplasms and without neoplasms, SOC showed small significant indirect effects on stress that were statistically mediated by mental well-being. Higher SOC was related to higher well-being which was, in turn, related to lower stress. The corresponding indirect effect sizes $\mathrm{ab}_{\mathrm{cs}}$ were $-0.1006, \mathrm{CI}_{95}(-0.1456,-0.0568),[-0.1039$, $\left.\mathrm{CI}_{95}(-0.1543,-0.0592)\right]$, and $-0.0800, \mathrm{CI}_{95}(-0.1004$, 0.0596), for patients with malignant and no neoplasms, respectively. In patients with benign neoplasms, no significant indirect effects of SOC were found; accordingly, effect sizes $\mathrm{ab}_{\text {cs }}$ were small: $0.0065, \mathrm{CI}_{95}(-0.0723$, 0.0844), [0.0143, $\left.\mathrm{CI}_{95}(-0.0684,0.0930)\right]$.

\section{Discussion}

This study investigated direct and indirect effects of SOC on perceived preoperative hospital and surgery related stress. Three simple mediation models with mental well-being as putative mediator were conducted in patients who underwent surgery due to malignant or benign neoplasms, or due to other diseases. In all three models, SOC showed substantial direct effects on perceived stress. Partly, SOC also showed indirect effects, although those were much smaller. As expected, patients who had a high SOC were less likely to experience preoperative hospital and surgery related stress. They also reported better mental well-being. In patients with benign neoplasms, however, this did not, and in those with malignant or no neoplasms, it did only slightly account for the relationship between SOC and lower preoperative stress.

\section{Preoperative stress in surgical patients with cancer}

To our knowledge, there are only few investigations comparing preoperative hospital and surgery related stress in patients with and without cancer. In the present study, patients with malignant, benign, and no neoplasms did not differ significantly regarding degrees of SOC, mental well-being, or clinically relevant depressive symptoms. However, patients who underwent surgery due to diseases without neoplasms reported significantly lower mean stress scores and lower rates of elevated hospital and surgery related stress than those who underwent surgery due to malignant and benign neoplasms. These results suggest that suffering from a neoplasm may be associated with clinically relevant and detrimental acute stress, but not necessarily with distress inducing lower SOC and / or lower mental-well-being. Our data are inconsistent with the findings of Domar et al. (1998) [25], but comparable with those of three previous studies that found higher preoperative state anxiety in cancer patients compared to non-cancer patients [22-24].

Research on preoperative stress is scarce in cancer patients. Preoperative stress was rarely assessed with explicit reference to the surgical and/or hospital context e.g. [67]. However, several studies measured unspecified state anxiety e.g. [22-24, 68-70], or general emotional distress before surgery e.g. [24, 71-75]. Altogether, preoperative stress in cancer patients was found to be related to adverse peri- and postoperative outcomes like higher pain, worse health-related quality of life, and increased incidence of delirium. These results resemble those of studies that did not explicitly focus on surgical patients with cancer [2, 7, 9-16]. While our investigation did not examine associations between stress and postoperative outcomes, it adds to the research on potential predictors of stress in cancer patients. The results suggest that the stress-reducing effect of SOC is not substantially mediated by an improvement of mental well-being, and that there might be other relevant factors to explain how SOC may relieve preoperative stress.

\section{Meaning in life as a specific resource of the stress buffering effect of SOC}

Our findings support the assumption that an understanding of one's life as meaningful, comprehensible, and manageable is directly linked to efficient stress regulation. This might be due to a stress buffering effect, allowing patients to draw on available resources to deal with the challenging situation of an upcoming surgery. Importantly, the direct effects of SOC on preoperative stress are of relatively similar seize in surgical patients with malignant, benign, and no neoplasms, supporting Antonovsky's conception that the associations of SOC and health-related factors are comparable over diverse diseases $[28,29]$. Thus, the question arises which specific psychological processes might be associated with the stress buffering effect of SOC. A large body of research has been carried out on effects of the central factor 
of SOC, meaning in life. These studies suggest that meaning in life activates a variety of psychological processes that are helpful for a successful coping with stressful life events and problems, such as better selfregulation skills, higher hopefulness and optimism, as well as experiences of competence, self-determination, and social integration [76-79].

\section{Limitations and future directions}

This study applied the BASOC to assess SOC. Like with other SOC measures, results based on the BASOC cannot be clearly attributed to one or more of the theorized underlying SOC facets of meaningfulness, comprehensibility, and manageability. Further research should use more specific measures, e.g. the meaningfulness and crisis of meaning scales from the Sources of Meaning and Meaning in Life Questionnaire, SoMe [45, 80]. Another limitation is the correlational design of the study that precludes conclusions concerning causality. SOC, mental well-being and preoperative stress were assessed preoperatively at the same time. Hence, without testing the mediation hypothesis with longitudinal data, no conclusions can be drawn concerning the causality of the relationship between SOC, mental well-being and preoperative stress; we can only claim a statistical mediation at this point [81]. Furthermore, our mediation models did not comprise additional oncological parameters as covariates, e.g. disease stage and time since cancer diagnosis. However, the models were adjusted for age and gender, as well as for substantial medical and surgical factors including physical health, surgical field, medical comorbidity, extent of surgical procedure, and site of tumor. As already mentioned, previous research did not find any moderator effects of disease stage and time since cancer diagnosis on the relationship between SOC and meaning in life, respectively, and psychological distress [33]. In the study at hand, the direct effects of SOC on stress were comparable in patients with malignant, benign, and no neoplasms. Both findings may suggest that the psychological processes associated with the relations of SOC and psychological outcomes might rather be independent of types of diseases and disease stages.

Taken together, future studies that aim to conduct analyses of effects of personal resources on acute stress in cancer patients should employ more specific measures and establish temporal precedence of the factors of the mediation model. Additionally, it would be interesting to explore whether the findings are robust when additional oncological patient characteristics are included as covariates in mediation models. Regarding relevant factors to explain how and under which conditions meaning in life and SOC may relieve preoperative stress, further potential mediators and moderators should be investigated, including factors like social support, self-regulation, socioeconomic status, diverse health behaviors, and measures of subjective health.

\section{Conclusions}

In this study, the rate of elevated perceived hospital and surgery related stress was relatively high, with $54.7,55.0$, and $42.0 \%$ in patients with malignant, benign, and no neoplasms, respectively. Contemporary approaches conceive of elevated preoperative stress as a clinically relevant negative patient reported outcome, irrespective of whether it is associated with worse postoperative surgical outcomes $[2,4]$. This perspective is consistent with psycho-oncological approaches that, independently of an upcoming surgery, consider emotional distress as a vital sign that requires treatment to improve the patients' mental health and health-related quality of life $[18,82-84]$. Our results can contribute to the improvement of treatment approaches by highlighting the necessity to reduce elevated preoperative stress. Among the psychological treatments that have shown to increase SOC and meaning in life are mindfulness-based and existential therapies. It would be worthwhile to explore to which extent these interventions are feasible and effective in acute and timerestricted preoperative settings. Nevertheless, it is also important to include interventions that do not primarily aim at increasing dispositional SOC or meaning in life. These interventions would explicitly support patients with low SOC by developing a trustful situational approach that communicates a preoperative atmosphere of meaningfulness, comprehensibility, and manageability. Within patientcentered communication, individual worries, doubts, and misunderstandings concerning the upcoming surgery should be explored and clarified. This may comprise providing medical information on specific surgeries and their chances of success, but most importantly, clarifications of the individual meaning of surgical procedures, and their necessity.

To conclude, we investigated a large sample $(n=4918)$ of patients with malignant, benign, and without neoplasms. In all three patient groups, SOC was directly associated with perceived hospital and surgery related stress, with higher SOC being related to lower stress. These results can inform treatment approaches to reduce elevated preoperative stress by specifically addressing low SOC.

\footnotetext{
Abbreviations

ASA: American Society of Anesthesiologists; BASOC: Brief Assessment of Sense of Coherence; BRIA: Bridging Intervention in Anesthesiology; CCl: Charlson Comorbidity Index; IQR: Interquartile range; OLS: Ordinary least square; POSSUM: Physiological and Operative Severity Score for the enUmeration of Mortality and Morbidity; SOC: Sense of Coherence; SOC-29: Sense of Coherence Scale 29; SoMe: Sources of Meaning and Meaning in Life Questionnaire; STAI: State Trait Anxiety Inventory; WHO-5: World Health Organization 5-item Well-Being Index
}

\section{Acknowledgements}

The authors wish to thank the teams of the preoperative anesthesiological assessment clinics and of BRIA, Department of Anesthesiology and Operative Intensive Care Medicine, CCM and CVK, Charité - Universitätsmedizin Berlin, for the excellent help with patient care, data collection and analysis. 


\section{Authors' contributions}

HK, TS, UG and CDS designed the study. HK, TS and UG carried out analysis and interpretation of data, and drafted the manuscript. LFK, ALS, and SG participated in the acquisition of data. SE, SG, ALS, and LFK participated in the literature searches. CDS and SE contributed to statistical analyses and interpretation of data. All authors discussed the results, commented on the paper, contributed to the critical revision of the manuscript, and read and approved the final manuscript.

\section{Funding}

This study was funded by a grant from the Deutsche

Forschungsgemeinschaft (DFG, German Research Foundation), Bonn, Germany (Grant KR 3836/3-1). The funder had no role in the design and conduct of the study, data collection, analysis and interpretation, decision to publish, or writing of the manuscript. Open Access funding enabled and organized by Projekt DEAL.

\section{Availability of data and materials}

Datasets of this study are not publicly available because study participants did not give their approval.

\section{Ethics approval and consent to participate}

This study was approved by the Ethics Committee of the Charite Universitätsmedizin Berlin [EA1/014/11]. All patients provided written informed consent.

\section{Consent for publication}

Not applicable.

\section{Competing interests}

The authors declare that they have no competing interests.

\section{Author details}

${ }^{1}$ Department of Anesthesiology and Operative Intensive Care Medicine (CCM, CVK), Charité - Universitätsmedizin, corporate member of Freie Universität Berlin, Humboldt-Universität zu Berlin, and Berlin Institute of Health, Charitéplatz 1, 10117 Berlin, Germany. ${ }^{2}$ Charité Comprehensive Cancer Center, Charité - Universitätsmedizin, corporate member of Freie Universität Berlin, Humboldt-Universität zu Berlin, and Berlin Institute of Health, Berlin, Germany. ${ }^{3}$ Department of Psychology, Faculty of Natural Sciences, Medical School Berlin, Berlin, Germany. ${ }^{4}$ Department of Anaesthesiology, Intensive Care, Emergency and Pain Medicine, Hospital Wolfenbuettel gGmbH, Wolfenbuettel, Germany. ${ }^{5}$ Institute of Psychology, University of Innsbruck, Innsbruck, Austria. ${ }^{6}$ Norwegian School of Theology, Religion and Society, Oslo, Norway.

Received: 2 May 2020 Accepted: 15 November 2020

Published online: 27 November 2020

\section{References}

1. Aust H, Eberhart L, Sturm T, Schuster M, Nestoriuc Y, Brehm F, Rusch D. A cross-sectional study on preoperative anxiety in adults. J Psychosom Res. 2018;111:133-9.

2. Caumo W. Nazare Furtado da Cunha M, Camey S, Maris de Jezus Castro S, Torres I, Cadore Stefani L. development, psychometric evaluation and validation of a brief measure of emotional preoperative stress (B-MEPS) to predict moderate to intense postoperative acute pain. $\mathrm{Br} J$ Anaesth. 2016; 117(5):642-9.

3. Eberhart L, Aust H, Schuster M, Sturm T, Gehling M, Euteneuer F, Rüsch D. Preoperative anxiety in adults - a cross-sectional study on specific fears and risk factors. BMC Psychiatry. 2020;20(1):140.

4. King A, Bartley J, Johanson DL, Broadbent E. Components of preoperative anxiety: a qualitative study. J Health Psychol. 2019;24(13):1897-908.

5. Laufenberg-Feldmann R, Kappis B. Assessing preoperative anxiety using a questionnaire and clinical rating: a prospective observational study. Eur J Anaesthesiol. 2013;30(12):758-63.

6. Moerman N, van Dam FS, Muller MJ, Oosting H. The Amsterdam preoperative anxiety and information scale (APAIS). Anesth Analg. 1996; 82(3):445-51.

7. Hernandez-Palazon J, Fuentes-Garcia D, Falcon-Arana L, Roca-Calvo MJ, Burguillos-Lopez S, Domenech-Asensi P, Jara-Rubio R. Assessment of preoperative anxiety in cardiac surgery patients lacking a history of anxiety: contributing factors and postoperative morbidity. J Cardiothorac Vasc Anesth. 2018;32(1):236-44.

8. Mitchell M. General anaesthesia and day-case patient anxiety. J Adv Nurs. 2010;66(5):1059-71.

9. Wilson C, Mitchelson A, Tzeng T, El-Othmani M, Saleh J, Vasdev S, LaMontagne H, Saleh K. Caring for the surgically anxious patient: a review of the interventions and a guide to optimizing surgical outcomes. Am J Surg. 2016:212:151-9.

10. Ip H, Abrishami A, Peng P, Wong J, Chung F. Predictors of postoperative pain and analgesic consumption: a qualitative systematic review. Anesthesiology. 2009;111:657-77.

11. Mavros M, Athanasiou S, Gkegkes I, Polyzos K, Peppas G, Falagas M. Do psychological variables affect early surgical recovery? PLoS One. 2011;6(5): e20306. https://doi.org/10.1371/journal.pone.0020306.

12. Powell R, Scott N, Manyande A, Bruce J, Vögele C, Byrne-Davis L, Unsworth M, Osmer C, Johnston M. Psychological preparation and postoperative outcomes for adults undergoing surgery under general anaesthesia. Cochrane Database Syst Rev. 2016;2016(5):Art. No.:CD008646. https://doi. org/10.1002/14651858.CD008646.pub2.

13. Rosenberger PH, Jokl P, Ickovics J. Psychosocial factors and surgical outcomes: an evidence-based literature review. J Am Acad Orthop Surg. 2006;14(7):397-405.

14. Strom J, Bjerrum MB, Nielsen CV, Thisted CN, Nielsen TL, Laursen M, Jorgensen LB. Anxiety and depression in spine surgery-a systematic integrative review. Spine J. 2018;18(7):1272-85.

15. Theunissen M, Peters M, Bruce J, Gramke H-F, Marcus M. Preoperative anxiety and catastrophizing: a systematic review and meta-analysis of the association with chronic postsurgical pain. Clin J Pain. 2012;28:819-41.

16. Walburn J, Vedhara K, Hankins M, Rixon L, Weinman J. Psychological stress and wound healing in humans: a systematic review and meta-analysis. J Psychosom Res. 2009;67:253-71.

17. Carlson LE, Waller A, Mitchell AJ. Screening for distress and unmet needs in patients with cancer: review and recommendations. J Clin Oncol. 2012;30(11):1160-77.

18. Donovan KA, Grassi L, McGinty HL, Jacobsen PB. Validation of the distress thermometer worldwide: state of the science. Psychooncology. 2014;23(3):241-50.

19. Ma X, Zhang J, Zhong W, Shu C, Wang F, Wen J, Zhou M, Sang Y, Jiang Y, Liu $L$. The diagnostic role of a short screening tool--the distress thermometer: a meta-analysis. Support Care Cancer. 2014;22(7):1741-55.

20. Mehnert A, Hartung TJ, Friedrich M, Vehling S, Brahler E, Harter M, Keller M, Schulz $\mathrm{H}$, Wegscheider $\mathrm{K}$, Weis J, Koch U, Faller H. One in two cancer patients is significantly distressed: prevalence and indicators of distress. Psychooncology. 2018;27(1):75-82.

21. Park S, Kang CH, Hwang Y, Seong YW, Lee HJ, Park IK, Kim YT. Risk factors for postoperative anxiety and depression after surgical treatment for lung cancerdagger. Eur J Cardiothorac Surg. 2016;49(1):e16-21.

22. Caumo W, Schmidt AP, Schneider CN, Bergmann J, Iwamoto CW, Bandeira D, Ferreira MB. Risk factors for preoperative anxiety in adults. Acta Anaesthesiol Scand. 2001;45(3):298-307.

23. Alves ML, Pimentel AJ, Guaratini AA, Marcolino JA, Gozzani JL, Mathias LA. Preoperative anxiety in surgeries of the breast: a comparative study between patients with suspected breast cancer and that undergoing cosmetic surgery. Rev Bras Anestesiol. 2007;57(2):147-56.

24. Masselin-Dubois A, Attal N, Fletcher D, Jayr C, Albi A, Fermanian J, Bouhassira D, Baudic S. Are psychological predictors of chronic postsurgical pain dependent on the surgical model? A comparison of total knee arthroplasty and breast surgery for cancer. J Pain. 2013;14(8):854-64.

25. Domar AD, Everett LL, Keller MG. Preoperative anxiety: is it a predictable entity? Anesth Analg. 1989;69(6):763-7.

26. Goebel S, Mehdorn HM. Assessment of preoperative anxiety in neurosurgical patients: comparison of widely used measures and recommendations for clinic and research. Clin Neurol Neurosurg. 2018;172:62-8.

27. Schubart JR, Emerich M, Farnan M, Stanley Smith J, Kauffman GL, Kass RB. Screening for psychological distress in surgical breast cancer patients. Ann Surg Oncol. 2014;21(10):3348-53.

28. Antonovsky A. Unraveling the mystery of health. San Franciso: Jossey-Bass; 1987.

29. Antonovsky A. The structure and properties of the sense of coherence scale. Soc Sci Med. 1993;36(6):725-33.

30. Eriksson M, Lindström B. Antonovsky's sense of coherence scale and the relation with health: a systematic review. J Epidemiol Community Health. 2006;60:376-81. 
31. Eriksson M, Lindstrom B. Antonovsky's sense of coherence scale and its relation with quality of life: a systematic review. J Epidemiol Community Health. 2007;61(11):938-44.

32. Huang IC, Lee JL, Ketheeswaran $P$, Jones CM, Revicki DA, Wu AW. Does personality affect health-related quality of life? A systematic review. PLoS One. 2017;12(3):e0173806.

33. Winger JG, Adams RN, Mosher CE. Relations of meaning in life and sense of coherence to distress in cancer patients: a meta-analysis. Psychooncology. 2016;25(1):2-10.

34. Hayes AF. Mediation, moderation, and conditional process analysis: a regression-based approach. 2nd ed. New York: Guilford Press; 2018.

35. Hayes AF, Rockwood NJ. Regression-based statistical mediation and moderation analysis in clinical research: observations, recommendations, and implementation. Behav Res Ther. 2017;98:39-57.

36. Glück TM, Tran US, Raninger S, Lueger-Schuster B. The influence of sense of coherence and mindfulness on PTSD symptoms and posttraumatic cognitions in a sample of elderly Austrian survivors of world war II. Int Psychogeriatr. 2016;28(3):435-41.

37. Grevenstein $D$, Bluemke $M$, Kroeninger-Jungaberle $H$. Incremental validity of sense of coherence, neuroticism, extraversion, and general self-efficacy: longitudinal prediction of substance use frequency and mental health. Health Qual Life Outcomes. 2016;14:9.

38. Krause N. Meaning in life and mortality. J Gerontol B Psychol Sci Soc Sci. 2009;64(4):517-27.

39. Vötter B, Schnell T. Cross-lagged analyses between life meaning, selfcompassion, and subjective well-being among gifted adults. Mindfulness. 2019;10(7):1294-303.

40. Czekierda K, Banik A, Park CL, Luszczynska A. Meaning in life and physical health: systematic review and meta-analysis. Health Psychol Rev. 2017;11(4): 387-418.

41. Kim G, Shin SH, Scicolone MA, Parmelee P. Purpose in life protects against cognitive decline among older adults. Am J Geriatr Psychiatry. 2019;27(6): 593-601.

42. Sinikallio S, Pakarinen M, Tuomainen I, Airaksinen O, Viinamaki H, Aalto TJ. Preoperative sense of coherence associated with the 10-year outcomes of lumbar spinal stenosis surgery. J Health Psychol. 2019;24(7):989-97.

43. Eriksson M, Mittelmark M. The sense of coherence and its measurement. In: Mittelmark M, Sagy S, Eriksson M, Bauer G, Pelikan J, Lindström B, et al., editors. The handbook of salutogenesis. Berlin: Springer International Publishing; 2017. p. 97-105.

44. Feldt $\mathrm{T}$, Leskinen $\mathrm{E}$, Koskenvuo M, Suominen S, Vahtera J, Kivimaki M. Development of sense of coherence in adulthood: a person-centered approach. The population-based HeSSup cohort study. Qual Life Res. 2011; 20(1):69-79.

45. Schnell T. The sources of meaning and meaning in life questionnaire (SoMe): relations to demographics and well-being. J Posit Psychol. 2009;4(3): 483-99.

46. Super S, Wagemakers MA, Picavet HS, Verkooijen KT, Koelen MA. Strengthening sense of coherence: opportunities for theory building in health promotion. Health Promot Int. 2016;31(4):869-78.

47. Bech P, Olsen L, Kjoller M, Rasmussen N. Measuring well-being rather than the absence of distress symptoms: a comparison of the SF-36 mental health subscale and the WHO-five well-being scale. Int J Methods Psychiatr Res. 2003;12(2):85-91.

48. Schougaard LMV, de Thurah A, Bech P, Hjollund NH, Christiansen DH. Test-retest reliability and measurement error of the Danish WHO-5 wellbeing index in outpatients with epilepsy. Health Qual Life Outcomes. 2018;16(1):175.

49. Topp CW, Ostergaard SD, Sondergaard S, Bech P. The WHO-5 well-being index: a systematic review of the literature. Psychother Psychosom. 2015; 84(3):167-76.

50. Carr E, Brockbank K, Allen S, Strike P. Patterns and frequency of anxiety in women undergoing gynaecological surgery. J Clin Nurs. 2006;15(3):341-52.

51. Kerper LF, Spies CD, Salz A-L, Weiß-Gerlach E, Balzer F, Neumann T, Tafelski S, Lau A, Neuner B, Romanczuk-Seiferth N, Glaesmer H, Wernecke K, Brähler E, Krampe $H$. Effects of an innovative psychotherapy program for surgical patients - bridging intervention in anesthesiology: a randomized controlled trial. Anesthesiology. 2015;123(1):148-59.

52. Krampe H, Salz A-L, Kerper L, Krannich A, Schnell T, Wernecke K-D, Spies C. Readiness to change and psychotherapy outcomes of an innovative psychotherapy program for surgical patients: results from a randomized controlled trial. BMC Psychiatry. 2017;17(417). https://doi.org/10.1186/ s12888-017-1579-5.

53. Kerper L, Spies CD, Buspavanich P, Balzer F, Salz A-L, Tafelski S, Lau A, WeißGerlach E, Neumann T, Glaesmer H, Wernecke K, Brähler E, Krampe H. Preoperative depression and hospital length of stay in surgical patients. Minerva Anestesiol. 2014;80(9):984-91.

54. Krampe H, Barth-Zoubairi A, Schnell T, Salz AL, Kerper LF, Spies CD. Social relationship factors, preoperative depression, and hospital length of stay in surgical patients. Int J Behav Med. 2018;25(6):658-68.

55. American Society of Anesthesiologists. New classification of physical status. Anesthesiology. 1963;24:111.

56. Wolters $U$, Wolf $T$, Stuetzer H, Schröder T. ASA classification and perioperative variables as predictors of postoperative outcome. $\mathrm{Br} \mathrm{J}$ Anaesth. 1996;77:217-22.

57. Kerper LF, Spies CD, Lößner M, Salz A-L, Tafelski S, Balzer F, Weiß-Gerlach E, Neumann T, Lau A, Glaesmer H, Brähler E, Krampe H. Persistence of psychological distress in surgical patients with interest in psychotherapy: results of a 6-month follow-up. PLoS One. 2012;7:e51167.

58. Charlson ME, Pompei P, Ales K, Mackenzie CR. A new method of classifying prognostic comorbidity in longitudinal studies: development and validation. J Chronic Dis. 1987;40(5):373-83.

59. Copeland GP, Jones D, Walters M. POSSUM: a scoring system for surgical audit. Br J Surg. 1991;78:356-60.

60. Noordzij PG, Poldermans D, Schouten O, Bax JJ, Schreiner FAG, Boersma E. Postoperative mortality in the Netherlands: a population-based analysis of surgery-specific risk in adults. Anesthesiology. 2010;112:1105-15.

61. Schumann A, Hapke U, Meyer C, Rumpf HJ, John U. Measuring sense of coherence with only three items: a useful tool for population surveys. $\mathrm{Br}$ J Health Psychol. 2003;8(Pt 4):409-21.

62. Linton MJ, Dieppe P, Medina-Lara A. Review of 99 self-report measures for assessing well-being in adults: exploring dimensions of well-being and developments over time. BMJ Open. 2016;6(7):e010641.

63. van Dijk SEM, Adriaanse MC, van der Zwaan L, Bosmans JE, van Marwijk HWJ, van Tulder MW, Terwee CB. Measurement properties of depression questionnaires in patients with diabetes: a systematic review. Qual Life Res. 2018;27(6):1415-30.

64. Roth AJ, Kornblith AB, Batel-Copel L, Peabody E, Scher HI, Holland JC. Rapid screening for psychologic distress in men with prostate carcinoma: a pilot study. Cancer. 1998:82(10):1904-8.

65. Spielberger $C$, Gorsuch R, Lushene R. Manual for the state-trait anxiety inventory. Palo Alto, CA: Consulting Psychologists Press; 1970.

66. Facco E, Stellini E, Bacci C, Manani G, Pavan C, Cavallin F, Zanette G. Validation of visual analogue scale for anxiety (VAS-A) in preanesthesia evaluation. Minerva Anestesiol. 2013;79(12):1389-95.

67. Bruce J, Thornton AJ, Powell R, Johnston M, Wells M, Heys SD, Thompson AM, Cairns Smith W, Chambers WA, Scott NW. Psychological, surgical, and sociodemographic predictors of pain outcomes after breast cancer surgery: a population-based cohort study. Pain. 2014; 155(2):232-43.

68. Katz J, Poleshuck EL, Andrus CH, Hogan LA, Jung BF, Kulick DI, Dworkin RH. Risk factors for acute pain and its persistence following breast cancer surgery. Pain. 2005;119(1-3):16-25.

69. Meretoja TJ, Leidenius MHK, Tasmuth T, Sipila R, Kalso E. Pain at 12 months after surgery for breast cancer. JAMA. 2014;311(1):90-2.

70. Miaskowski C, Paul SM, Cooper B, West C, Levine JD, Elboim C, Hamolsky D, Abrams G, Luce J, Dhruva A, Langford DJ, Merriman JD, Kober K, Baggott C, Leutwyler $\mathrm{H}$, Aouizerat BE. Identification of patient subgroups and risk factors for persistent arm/shoulder pain following breast cancer surgery. Eur J Oncol Nurs. 2014;18(3):242-53.

71. Belfer I, Schreiber KL, Shaffer JR, Shnol H, Blaney K, Morando A, Englert D, Greco C, Brufsky A, Ahrendt G, Kehlet H, Edwards RR, Bovbjerg DH. Persistent postmastectomy pain in breast cancer survivors: analysis of clinical, demographic, and psychosocial factors. J Pain. 2013;14(10):1185-95.

72. Hao-Hsien L, Chong-Chi C, Jin-Jia L, Jhi-Joung W, King-Teh L, Ding-Ping S, Hon-Yi S. Impact of preoperative anxiety and depression on quality of life before and after resection of hepatocellular carcinoma. J Affect Disord. 2019;246:361-7.

73. Mejdahl MK, Mertz GB, Bidstrup PE, Andersen KG. Preoperative distress predicts persistent pain after breast cancer treatment: a prospective cohort study. J Natl Compr Cancer Netw. 2015;13(8):995-1003. 
74. Spivey TL, Gutowski ED, Zinboonyahgoon N, King TA, Dominici L, Edwards RR, Golshan M, Schreiber KL. Chronic pain after breast surgery: a prospective, observational study. Ann Surg Oncol. 2018;25(10):2917-24.

75. Wada S, Inoguchi H, Sadahiro R, Matsuoka YJ, Uchitomi Y, Sato T, Shimada K, Yoshimoto S, Daiko H, Shimizu K. Preoperative anxiety as a predictor of delirium in cancer patients: a prospective observational cohort study. World J Surg. 2019;43(1):134-42.

76. Schnell T. The psychology of meaning in life. New York, Abingdon: Routledge; 2020.

77. Damásio BF, Koller SH, Schnell T. Sources of meaning and meaning in life questionnaire (SoMe): psychometric properties and sociodemographic findings in a large Brazilian sample. Acta Invest Psicol. 2013;3(3):1205-27.

78. Hanfstingl B. Ego and spiritual transcendence: relevance to psychological resilience and the role of age. Evid Based Complement Alternat Med. 2013; 949838. https://doi.org/10.1155/2013/949838.

79. Kashdan TB, Breen WE. Materialism and diminished well-being: experiential avoidance as a mediating mechanism. J Soc Clin Psychol. 2007;26(5):521-39.

80. Schnell T. An empirical approach to existential psychology: meaning in life operationalized. In: Kreitler S, Urbanek T, editors. Conceptions of meaning. New York: Nova Science; 2014. p. 173-94.

81. Maxwell SE, Cole DA. Bias in cross-sectional analyses of longitudinal mediation. Psychol Methods. 2007;12(1):23-44.

82. Bultz BD, Johansen C. Screening for distress, the 6th vital sign: where are we, and where are we going? Psychooncology. 2011;20(6):569-71.

83. Faller $\mathrm{H}$, Weis J, Koch U, Brahler E, Harter M, Keller M, Schulz H, Wegscheider K, Boehncke A, Hund B, Reuter K, Richard M, Sehner S, Szalai C, Wittchen $H U$, Mehnert A. Perceived need for psychosocial support depending on emotional distress and mental comorbidity in men and women with cancer. J Psychosom Res. 2016;81:24-30.

84. Goerling U, Mehnert A. Future research in psycho-oncology. In: Goerling U, Mehnert A, editors. Psycho-Oncology, second edition. Recent results in cancer research. 2017/09/20 ed. Cham: Springer; 2018. p. 223-34.

\section{Publisher's Note}

Springer Nature remains neutral with regard to jurisdictional claims in published maps and institutional affiliations.

Ready to submit your research? Choose BMC and benefit from:

- fast, convenient online submission

- thorough peer review by experienced researchers in your field

- rapid publication on acceptance

- support for research data, including large and complex data types

- gold Open Access which fosters wider collaboration and increased citations

- maximum visibility for your research: over $100 \mathrm{M}$ website views per year

At $\mathrm{BMC}$, research is always in progress.

Learn more biomedcentral.com/submissions 